\title{
Penyuluhan Pendidikan Lingkungan Hidup sebagai Upaya Peningkatan Ekoliterasi Sekolah Berbasis Creative Learning
}

\author{
Herda Sabriyah Dara Kospa ${ }^{1}$, Atidira Dwi Hanani ${ }^{2}$, Zenal Mutaqin ${ }^{3}$, Imron ${ }^{4}$ \\ ${ }^{1,3}$ Program Studi Perencanaan Wilayah dan Kota, Universitas Indo Global Mandiri, Palembang, Indonesia \\ ${ }^{2,4}$ Program Studi Kesehatan dan Keselamatan Kerja (K3), Universitas Indo Global Mandiri, Palembang, \\ Indonesia
}

DOI: https://doi.org/10.29303/ipmsi.v2i2.56

Citation: Kospa, H. S. D., Hanani, A. d., Mutaqin, Z., Imron, I . 2020. Penyuluhan Pendidikan Lingkungan Hidup sebagai Upaya Peningkatan Ekoliterasi Sekolah Berbasis Creative Learning. Jurnal Pengabdian Masyarakat Sains Indonesia (JPMSI). 2(2):173-176 .

\section{Article history}

Received: October $08^{\text {th }} 2020$

Revised: October $30^{\text {th }} 2020$

Accepted: December $28^{\text {th }} 2020$

*Corresponding Author: Herda Sabriyah Dara Kospa, Universitas Indo Global Mandiri, Palembang, Indonesia;

Email: darakospa@uigm.ac.id

\begin{abstract}
Abstrak: Pendidikan lingkungan hidup yang diberikan sejak dini di sekolah dasar merupakan upaya penting yang dapat dilakukan untuk menanamkan perilaku peduli lingkungan terhadap anak. Para siswa diharapkan menjadi agen perubahan yang dapat mempromosikan upaya konservasi lingkungan di sekolah, keluarga dan masyarakat. Akan tetapi, banyak kendala dan hambatan yang menyebabkan pendidikan lingkungan hidup ini tidak dapat diikuti oleh semua sekolah, antara lain: belum adanya komitmen dari pemerintah daerah maupun pihak sekolah untuk mewajibkan penerapan pendidikan lingkungan ke dalam perda, maupun pada kebijakan dan kurikulum sekolah. Selain itu, pengunaan metode dan media yang kurang aplikatif dan inovatif menyebabkan siswa tidak dapat memahami materi secara utuh. Melalui metode creative learning, kegiatan pengabdian ini bertujuan untuk meningkatkan pengetahuan, sikap dan perilaku siswa dalam berperilaku hidup bersih dan sehat (PHBS) dan kesadaran dalam pengelolaan lingkungan. Kegiatan yang dilakukan antara lain memberikan sosialisasi dan pelatihan PHBS dan konservasi lingkungan kepada seluruh elemen sekolah agar dapat berpartisipasi aktif dalam kegiatan pelestarian lingkungan. Menggunakan metode kreatif berbasis permainan diharapkan dapat memudahkan siswa memahami materi secara komprehensif dan menerapkannya dalam kehidupan sehari-hari.
\end{abstract}

Kata kunci: Penyuluhan; Pendidikan Lingkungan Hidup; PHBS; Creative Learning

\section{Pendahuluan}

Meningkatkan kesadaran dan keinginan manusia untuk melakukan perlindungan dan pengelolaan terhadap lingkungan hidup dapat dilakukan melalui pendidikan lingkungan hidup. Sejarah panjang pendidikan lingkungan telah ada sejak abad ke-19, namun terdapat banyak kendala dan hambatan dalam perkembangannya terutama penerapannya di Indonesia. Melalui program Adiwiyata, hingga saat ini kebijakan yang telah ada hanya bersifat bilateral atau lebih berfokus pada kerjasama antar instansi (misalnya $\mathrm{MoU}$ antara KemenLH dan Departemen Pendidikan Nasional), sementara itu belum ada perda yang secara spesifik mengatur pelaksanaan pendidikan lingkungan hidup. Di samping itu, belum adanya komitmen dari pelaku pendidikan juga berpengaruh terhadap keberhasilan program tersebut. Masih ada kebijakan yang tidak pro terhadap pendidikan lingkungan karena beranggapan tidak begitu penting, mengakibatkan terbatasnya ruang kreativitas pendidik untuk mengajarkan secara komprehensif (Adisendjaja, 2007; Steele, et al. 2015). 
Kospa et al, Jurnal Pengabdian Masyarakat Sains Indonesia 2020, 2 (2):173-176. DOI : https://doi.org/10.29303/jpmsi.v2i2.56

Adapun kendala secara teknis dalam proses pengajaran pendidikan lingkungan hidup adalah materi dan metode pembelajarannya yang belum memadai dan tidak aplikatif, sehingga pemahaman kelompok sasaran menjadi tidak utuh (Adisendjaja, 2007; Steele, et al. 2015; Muslicha, 2015). Ditambah lagi dengan kesalahan mindset bahwa dibutuhkan sarana prasarana berteknologi tinggi untuk mendukung pendidikan lingkungan, sehingga menurunkan motivasi untuk menerapkan pendidikan lingkungan hidup (Adisendjaja, 2007; Steele, et al. 2015). Hal ini berdampak pada perilaku siswa yang belum menerapkan PHBS dan tidak menjaga lingkungan, seperti membuang sampah sembarangan dan jajan makanan yang tidak sehat, sehingga mudah terserang penyakit.

Di Palembang tidak banyak sekolah dasar terutama swasta yang mengikuti program pendidikan lingkungan hidup. Setiap tahunnya pemberian penghargaan Adiwiyata didominasi oleh sekolah-sekolah negeri dan unggulan, sehingga perlu adanya upaya untuk memberikan pembinaan kepada sekolah-sekolah yang belum terjangkau oleh program tersebut dan belum mendapatkan perhatian penuh oleh pemerintah. Salah satunya adalah MI Nurul Falah yang berlokasi di antara permukiman padat penduduk di Kelurahan 30 Ilir Palembang.

Madrasah Ibtidaiyah (MI) Nurul Falah merupakan lembaga pendidikan swasta setingkat sekolah dasar yang dikelola oleh Yayasan Nurul Falah. Kegiatan operasional sekolah ini dibiayai oleh Kementerian Agama melalui program Bantuan Operasional Sekolah (BOS). Ditujukan untuk masyarakat ekonomi lemah, Yayasan MI Nurul Falah selama beroperasinya tidak memungut biaya iuran kepada siswanya, bahkan sepuluh persen jumlah alokasi siswa ditujukan bagi anak yatim yang tidak mampu.

Kegiatan pengabdian ini merupakan bagian dari hasil penelitian yang dilakukan oleh Kospa dan Rahmadi (2019) yang berjudul "Pengaruh Perilaku Masyarakat terhadap Kualitas Air Di Sungai Sekanak Kota Palembang" dan "Analisis Kualitas Air dan Strategi Pengendalian Pencemaran Air Sungai Sekanak Kota Palembang (Kospa dan Rahmadi, 2019)". Salah satu hasil perumusan strategi untuk melakukan pengendalian pencemaran sungai akibat limbah domestik tersebut adalah melalui penerapan pendidikan lingkungan dan sosialisasi rutin untuk meningkatkan kesadaran masyarakat terhadap lingkungan.
e-ISSN : 2715-2537

p-ISSN : 2715-2545

\section{Metode}

Metode pelaksanaan kegiatan pengabdian kepada masyarakat ini dilakukan sebagai upaya peningkatan ekoliterasi siswa dan guru melalui pengembangan program pendidikan lingkungan hidup yang ada dengan menggunakan berbagai metode pembelajaran kreatif (Creative Learning).

Berdasarkan studi efektifitas metodemetode pengajaran, pengunaan metode pengalaman langsung, diskusi dan demonstrasi, serta eksperimen secara berturut-turut lebih efektif dalam pengajaran di sekolah dasar Adiwiyata (Muslicha, 2015). Tujuan menggunakan metode tersebut adalah memudahkan siswa memahami materi pembelajaran melalui beragam media yang menyenangkan, seperti video, film, permainan atau disebut Game-based Leaning, dongeng, karyawisata atau fieldtrip dan praktek langsung ke lapangan dalam Project-based Learning.

Kegiatan tersebut berguna untuk meningkatkan pengetahuan, sikap dan perilaku siswa sejak dini terhadap perilaku hidup bersih dan sehat (PHBS) dan melakukan pengelolaan lingkungan. Di samping itu, keberhasilan penerapan penyuluhan ini juga dapat mempengaruhi keputusan siswa dalam pembelian produk-produk yang berbahan baku ramah lingkungan (Ulumiyah dan Harti. 2017), serta berpengaruh positif terhadap minat belajar siswa (Rahmah, 2017).

Selain itu, kegiatan penyuluhan juga dilakukan kepada jajaran pimpinan dan guru MI Nurul Falah mengenai penerapan program Pendidikan Lingkungan Hidup (PLH) di lingkungan sekolah. Hal ini bertujuan untuk mendorong sekolah untuk membuat dan menerapkan kurikulum yang berbasis lingkungan hidup pada semua subjek studi. Selain itu, diharapkan agar guru dapat membuat kegiatan ekstrakurikuler yang bertema lingkungan hidup, seperti kegiatan pada hari Lingkungan Hidup sedunia, Hari Air sedunia, dsb, sehingga menghidupkan rasa kepedulian siswa terhadap isuisu lingkungan.

\section{Hasil dan Pembahasan}

Penyuluhan Pendidikan Lingkungan Hidup Kepada Siswa Berbasis Creative Learning

Kegiatan pendidikan lingkungan berbasis pembelajaran kreatif diberikan kepada siswa/i MI Nurul Falah Palembang untuk seluruh jenjang kelas 
Kospa et al, Jurnal Pengabdian Masyarakat Sains Indonesia 2020, 2 (2):173-176. DOI : https://doi.org/10.29303/jpmsi.v2i2.56

1 hingga 6 dan dilaksanakan pada 14 Agustus dan 24 September 2020. Dengan mengikuti protokol kesehatan yang benar, siswa/i yang hadir dibagi menjadi 3 (tiga) sesi per hari dimana setiap sesi hanya terdiri dari 12 - 14 orang siswa dengan duduk berjarak 1 meter. Selain itu, mereka diwajibkan mencuci tangan sebelum massuk dan menggunakan masker. Masker gratis juga diberikan kepada siswa ditambah dengan beberapa peralatan sekolah seperti pena, buku, kotak pensil dan crayon.
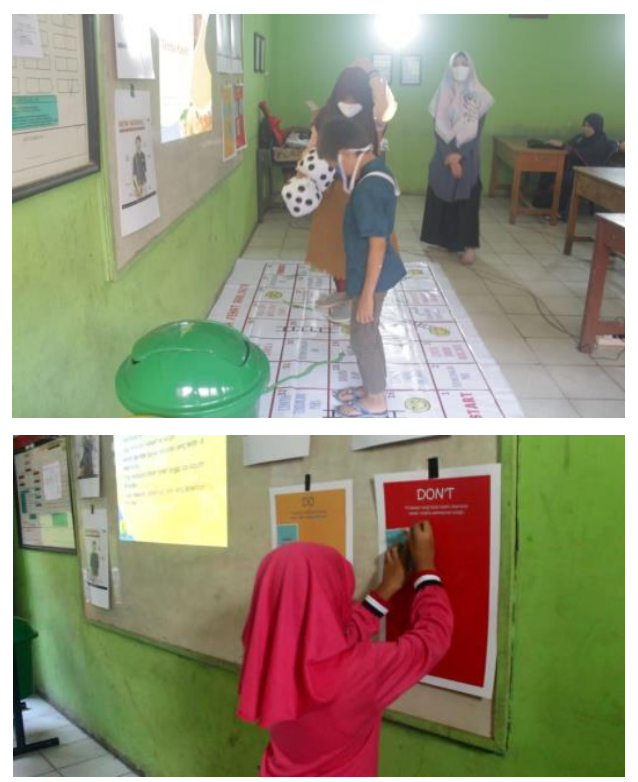

Gambar 1 Kegiatan penyuluhan lingkungan berbasis permainan kreatif

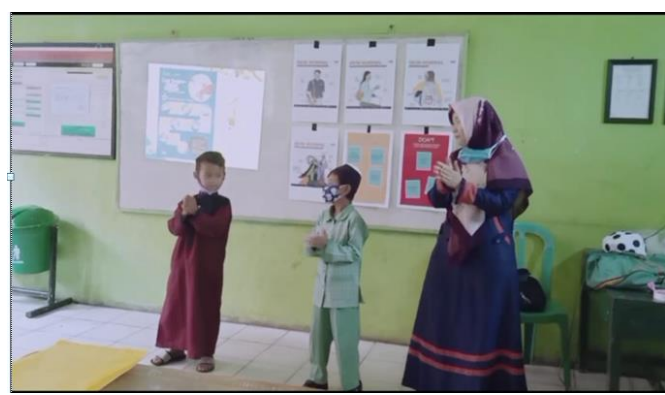

Gambar 2 Siswa memperagakan cara mencuci tangan yang benar

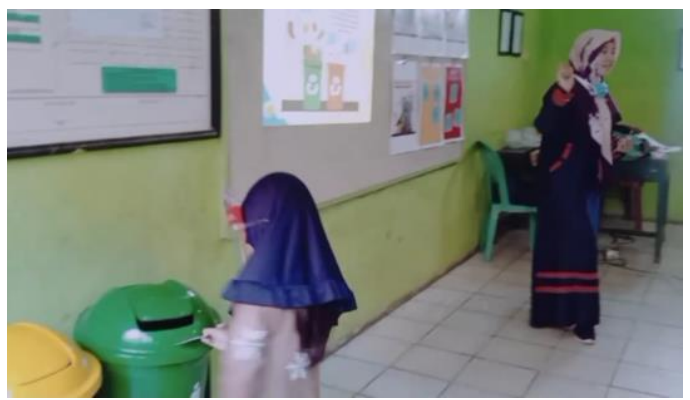

Gambar 3 Siswa memasukkan kartu bergambar sampah ke dalam kotak sampah organik/nonorganik
e-ISSN : $2715-2537$

p-ISSN : 2715-2545

Untuk mengukur efektivitas materi yang diberikan, evaluasi diberikan kepada siswa sebelum dan sesudah penyuluhan (pre-test dan post-test). Peserta mengisi lembar pertanyaan yang diberikan sebelum materi disampaikan dan pertanyaan kembali diberikan setelah penyuluhan dilakukan. Hasil evaluasi tersebut menunjukkan kegiatan penyuluhan tersebut berdampak positif bagi mitra dimana terjadi peningkatan ekoliterasi siswa dalam hal PHBS dan pengelolaan lingkungan dimana ratarat nilai siswa lebih tinggi setelah post test dilakukan.

\section{Penyuluhan tentang Implementasi Pendidikan Lingkungan Hidup Kepada Guru}

Kegiatan penyuluhan terhadap pimpinan yayasan, guru, dan karyawan di lingkungan MI Nurul Falah juga telah dilakukan pada 24 September 2020. Kegiatan ini bertujuan untuk mengedukasi dan mengajak seluruh elemen sekolah untuk berpartisipasi aktif dalam pelestarian lingkungan hidup, terutama dalam melakukan implementasi pendidikan lingkungan hidup melalui kegiatan belajar mengajar.

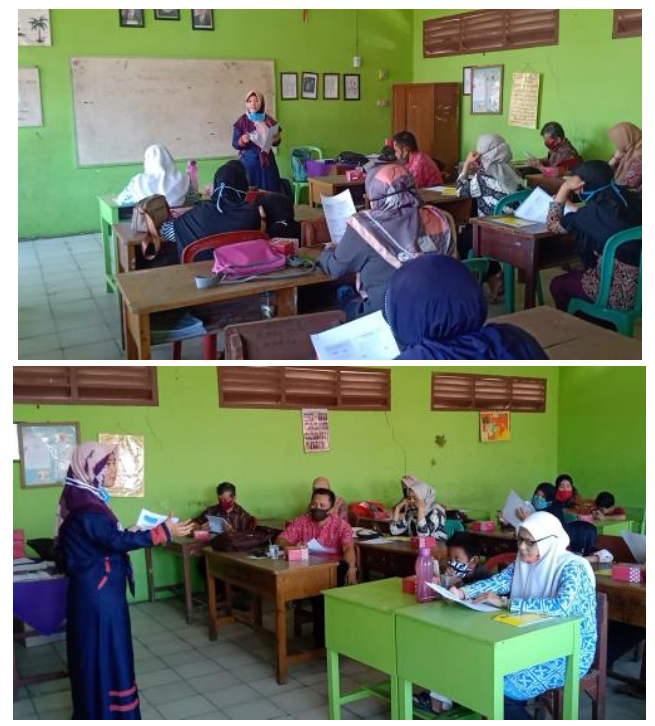

Gambar 4 Penyuluhan kepada guru tentang implementasi pendidikan lingkungan hidup

Upaya untuk mengukur efektivitas penyuluhan ini, dilakukan dengan menyebarkan kuesioner kepada seluruh peserta penyuluhan setelah pelaksanaan program tersebut. Peserta mengisi pertanyaan terkait persepsi dan kesediaannya dalam mengadopsi kurikulum dan kebijakan berbasis lingkungan. Hasil kuesioner 
Kospa et al, Jurnal Pengabdian Masyarakat Sains Indonesia 2020, 2 (2):173-176. DOI : https://doi.org/10.29303/jpmsi.v2i2.56

tersebut menunjukkan sekitar $80 \%$ peserta bersedia untuk mengadopsi kurikulum berbasis lingkungan hidup dan membuat ektrakurikuler berwawasan lingkungan di MI Nurul Falah.

\section{Kesimpulan}

Kegiatan pengabdian masyarakat stimulus ini menghasilkan beberapa simpulan sebagai berikut:

1. Kegiatan penyuluhan pendidikan lingkungan hidup berbasis creative learning ini dapat meningkatkan pengetahuan mitra, yaitu siswa/I MI Nurul Falah tentang perilaku hidup bersih dan sehat (PHBS) dan pengelolaan lingkungan.

2. Penyuluhan tentang implementasi pendidikan lingkungan hidup dapat meningkatkan pengetahuan pimpinan, guru dan karyawan MI Nurul Falah dalam mendorong kegiatan belajar mengajar yang berwawasan lingkungan.

\section{Saran}

Kegiatan pengabdian ini dilakukan dalam kondisi pandemic Covid-19, sehingga beberapa aktivitas yang dilakukan di ruangan publik guna menghadirkan pengalaman siswa dalam kegiatan pelestarian lingkungan, seperti berkunjungan ke hutan kota dan kebun binatang, serta melihat kondisi sungai tidak dapat dilakukan. Diharapkan penerapan kegiatan ini dapat dilakukan dengan maksimal pada kegiatan penyuluhan berikutnya.

\section{Ucapan Terima Kasih}

Penulis mengucapkan terima kasih kepada Direktorat Riset dan Pengabdian Masyarakat Deputi Bidang Penguatan Riset dan Pengembangan Kementrian Riset dan Teknologi/Badan Riset dan Inovasi Nasional yang telah memberi dukungan financial terhadap kegiatan Pengabdian Kepada Masyarakat ini.

\section{Daftar Pustaka}

Adisendjaja, Y.H. 2007. Penerapan Pendidikan Lingkungan Di Sekolah. Disampaikan pada Seminar Open Mind Jurusan Biologi FKIP Universitas Pasundan,
e-ISSN : 2715-2537

p-ISSN : 2715-2545

http://file.upi.edu/Direktori/FPMIPA/JUR.

PEND._BIOLOGI/195512191980021-

YUSUF_HILMI_ADISENDJAJA/PENER

APAN PENDIDIKAN LINGKUNGAN

DI_SEKOLAH.pdf diakses pada 31

Agustus 2019

Kospa, H.S.D. 2019. Pengaruh Perilaku Masyarakat terhadap Kualitas Air Di Sungai Sekanak Kota Palembang. Jurnal Ilmu Lingkungan Universitas Diponegoro. Vol.17(2)2019 ISSN: $1829-8907$.

.2019. Analisis Kualitas Air dan Strategi Pengendalian Pencemaran Air Sungai Sekanak Kota Palembang. Prosiding Seminar Nasional Hari Air Dunia 2019.eISSN:2621-7469.

Muslicha, A. 2015. Metode Pengajaran dalam Pendidikan Lingkungan Hidup pada Siswa Sekolah Dasar (Studi pada Sekolah Adiwiyata DKI Jakarta). Jurnal Pendidikan Vol. 16 (2) hal. 110-126.

Rahmah, U. 2017. Pengaruh Penerapan Green School Terhadap terhadap Minat Belajar Siswa di SMPN 26 Surabaya. Jurnal Institut Agama Islam Negeri Madura At-Turas Vol. IV (2) hal.153-171.

Steele, et al. 2015. Review Implementasi Pendidikan Lingkungan di Provinsi Jambi. Seminar Nasional XII Pendidikan Biologi FKIP Universitas Negeri Sebelas Maret. Diakses online pada 31 Agustus 2019 https://media.neliti.com/media/publications /171791-ID-review-implementasipendidikan-lingkunga.pdf

Ulumiyah, A dan Harti. 2017. Pengaruh Pengetahuan Eco-school Terhadap Keputusan Pembelian Green Product pada Siswa SMAN 9 Surabaya. Jurnal Universitas Negeri Surabaya. 